\section{Partial agonism and schizophrenia}

\author{
A. A. BOLONNA and R.W. KERWIN
}

Recent literature on partial agonists has generated interest in their therapeutic potential in schizophrenia. This has been driven, in part, by the recent approval of the dopamine (D2) receptor partial agonist aripiprazole in the USA and Europe. In comparison with conventional and atypical antipsychotics that mediate their therapeutic effects by D2 receptor blockade, aripiprazole has a unique mechanism of action. However, the concept of partial agonists for the treatment of schizophrenia is not entirely novel, since aripiprazole is one of several members of this class of drug. This editorial reviews the neurochemistry of dopamine in schizophrenia and discusses the theoretical importance of partial agonism as a mechanism for the treatment of this illness. We also summarise the historical information on previous trials of partial agonists in schizophrenia and evaluate other dopamine receptor partial agonists that are currently under development.

\section{WHAT IS A PARTIAL AGONIST?}

Two fundamental properties of a drug determine its effect on a receptor: affinity, the propensity of a drug to form a reversible complex with its receptor, and efficacy (or intrinsic activity), the ability of a drug to produce a functional response (Stephenson, 1956; Ariens \& Simonis, 1964). For a given receptor, a drug can produce a maximal response (full agonist) or have no functional effect (full antagonist). Full agonists are traditionally naturally occurring compounds (e.g. dopamine) and full antagonists are chemical entities produced by pharmaceutical chemists. In reality, the majority of chemically related drugs acting at a receptor produce a spectrum of functional responses that lie between full agonism and full antagonism (Ariens, 1964). These drugs are termed 'partial agonists' because they have a lower intrinsic activity than full agonists. Partial agonists can elicit different receptor responses depending on their environment: in the presence of agonists with higher intrinsic activity, partial agonists can demonstrate antagonist properties by blocking access to the receptor, but on their own they will act as agonists (Fig. 1). There are numerous reports of partial agonists that act at the D2 receptor; those of relevance to the treatment of schizophrenia are discussed in detail below.

\section{WHY IS A PARTIAL AGONIST OF THEORETICAL INTEREST IN SCHIZOPHRENIA?}

The original dopamine hypothesis of schizophrenia proposed an excess of dopaminergic activity as the fundamental neurochemical abnormality in the disorder (Carlsson \& Lindqvist, 1963). This was based in part on the observation that typical antipsychotics such as chlorpromazine alleviated schizophrenia symptoms by antagonising D2 receptors. Hence, dopamine receptor antagonists were considered the ideal therapeutic intervention in schizophrenia. In later years, the pharmacology of atypical antipsychotic agents such as clozapine and quetiapine led to a reassessment of these assumptions; atypicals demonstrated relatively low affinities for dopamine receptors, but were also effective in the treatment of schizophrenia (Pilowsky et al, 1992; Kapur et al, 2000). Atypical antipsychotics are superior to conventional antipsychotics in the treatment of negative symptoms and are less likely to cause extrapyramidal sideeffects (Kerwin \& Osborne, 2000), which has been attributed to their targeting of neurotransmitter systems other than dopamine, in particular the serotonergic system (Meltzer, 1999). Thus, the search for relevant drug targets was broadened to encompass other neurotransmitter receptors; however, this approach has met with modest success. It is apparent, though, that all effective antipsychotics to date incorporate D2 receptor antagonism in their mechanism of action; therefore, the current drug discovery process aims to identify drugs that primarily target the dopaminergic system with greater therapeutic efficacy (Kapur \& Mamo, 2003). When considering the potential benefits of dopamine receptor partial agonists in the treatment of schizophrenia, two functional aspects of the dopaminergic system require consideration: the postulated reciprocal dysregulation of cortical and subcortical dopamine systems, and the role of dopamine autoreceptors in schizophrenia.

\section{DUAL PATHOLOGY}

The original dopamine hypothesis for schizophrenia was based on the belief that dopamine only innervated subcortical regions, and that these regions were overstimulated by excessive dopamine transmission (Seeman \& Lee, 1975; Creese et al, 1976). However, advances in biochemical and behavioural techniques led to the identification of additional cortical dopamine projections (Thierry et al, 1973) which responded in an opposite way to subcortical dopamine systems: loss of frontal cortical dopamine function increased motor activity, in direct contrast to the observations following stimulation of dopamine receptors in extrapyramidal or mesolimbic regions (Carter \& Pycock, 1979). This seminal study and subsequent animal lesion experiments showed an opposite and reciprocal regulation of cortical and subcortical dopamine systems, leading the authors to propose that the fundamental neurochemical lesion in schizophrenia involved a deficit in frontal cortical dopamine and an increase in subcortical dopamine function (Pycock et al, 1980a,b).

Following these early reports, neuroimaging studies and neuropsychological tests on people with schizophrenia demonstrated impaired functioning of the frontal lobe (hypofrontality) (Weinberger \& Berman, 1996), and a correlation with negative symptoms (Andreasen et al, 1992) and reduced dopaminergic activity (Weinberger et al, 1988; Egan et al, 2001). Furthermore, cortical D1 receptor levels are reduced in patients with schizophrenia (Abi Dhargam $\&$ Moore, 2003). In contrast to the findings in the frontal lobe, amphetamine-induced excess release of dopamine in the striatum 


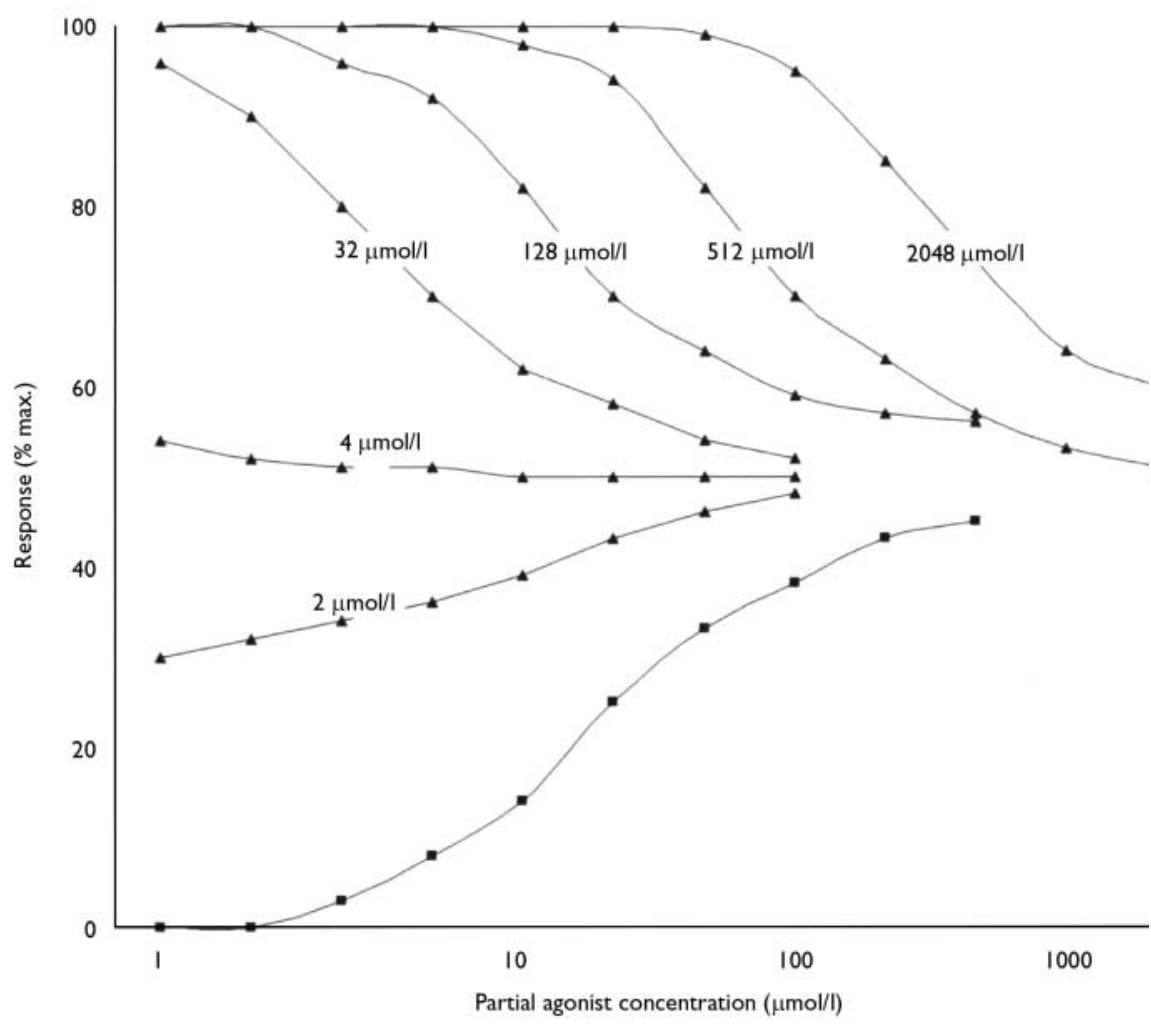

Fig. I Theoretical representation of receptor response to a full agonist and a partial agonist. This was initially demonstrated with muscarone-related compounds on isolated rat jejunum (Ariens et al, 1964). In the absence of the full agonist, the partial agonist behaves as an agonist (squares), but produces a lower maximal response than the full agonist. At higher concentrations of the full agonist (triangles), the partial agonist acts as an antagonist.

(subcortical region) of patients with schizophrenia compared with controls indicates a hyperactive subcortical dopamine system in schizophrenia (Breier et al, 1997). Overactivity of the striatum was also associated with positive symptoms of schizophrenia (Breier et al, 1997).

Thus, numerous studies on schizophrenia patients support the initial concept of Pycock and colleagues and a subsequent revised dopamine hypothesis of schizophrenia, which proposed that hyperactive mesolimbic (subcortical) dopamine tracts contributed to the positive symptoms of schizophrenia and underactive mesocortical (cortical) dopamine pathways played a part in negative symptoms and cognitive impairment (Weinberger, 1987). This postulated imbalance of dopamine function in frontal and subcortical regions may be a relevant therapeutic target in schizophrenia. Hence, a dopamine receptor partial agonist (bearing in mind that partial agonism is a relative concept) could act as a dopamine stabiliser by increasing dopamine activity in the frontal cortex dysregulated dopamine release in schizophrenia (Grunder et al, 2003). However, it has been suggested that dopamine autoreceptor antagonists (sulpiride and amisulpride) also stabilise dopamine systems in schizophrenia by increasing dopamine release and selectively blocking D2 and D3 receptors in the limbic system (Kerwin, 2000).

\section{PARTIAL AGONISTS: OLD AND NEW}

The concept of partial agonists in the correction of dysfunctional cortical and subcortical connectivity in schizophrenia dates back to the 1970s. Dopamine receptor partial agonists, by virtue of their unique mechanism of action, potentially represent a distinct class of atypical antipsychotics. All clinically effective antipsychotics mediate their therapeutic effects by blockade of D2 receptors; partial agonists are postulated to improve symptoms by stabilising dysregulated cortical and subcortical dopamine systems without generating the side-effects (movement disorders and hyperprolactinaemia) that are associated with non-specific D2 receptor blockade of the nigrostriatal and tuberoinfundibular pathways (Richelson, 1999).

One well-known partial agonist for the treatment of schizophrenia was (-)3-(3-hydroxyphenyl)- $N$-n-propylpiperidine, known as (-)-3PPP or preclamol. This compound targets D2-like receptor subtypes and is selective for the dopamine autoreceptor (Clark et al, 1985; Chio et al, 1994). Placebo-controlled studies indicated rapid improvements in positive and negative symptoms without the generation of motor side-effects (Lahti et al, 1998). However, this effect was not sustained beyond 1 week, possibly owing to desensitisation of the dopamine autoreceptor. Other dopamine partial agonists that have undergone trials in schizophrenia include talipexole (B-HT 920), roxindole (EMD 49980) and SDZ-HDC 912, but their effects on the symptoms of schizophrenia were, at best, similar to conventional antipsychotics or not sustained at therapeutic doses (Ohmori et al, 1993; Wetzel et al, 1994). This variability in therapeutic effects may relate to differences in the intrinsic activity of each partial agonist at dopamine receptors (Tamminga, 2002). However, two recent dopamine receptor partial agonists (aripiprazole and bifeprunox) are promising 
candidates for the treatment of schizophrenia (see below).

\section{Modern partial agonists in the treatment of schizophrenia}

\section{Aripiprazole}

Aripiprazole (OPC-14597), a Bristol-Myers Squibb/Otsuka Pharmaceutical Co. Ltd compound, has received approval by the US Food and Drug Administration and in Europe. Preclinical and clinical studies have highlighted aripiprazole as a potential prototype of a new generation of atypical antipsychotics that are dopamine system stabilisers. Preclinical studies classified aripiprazole as a potent D2 receptor partial agonist (Burris et al, 2002). Additional evidence of aripiprazole's partial agonist properties was gained from animal models of dopamine hyperactivity and hypoactivity: aripiprazole demonstrated antagonism of D2 receptors by suppressing apomorphine-induced stereotypy (dopamine hyperactivity model), and D2 agonist properties by blocking enhanced dopamine synthesis in rats treated with reserpine (dopamine hypoactivity model) (Kikuchi et al, 1995). The stabilising effect of aripiprazole on the dopamine system was attributed to its targeting of presynaptic (autoreceptors) and post-synaptic D2 receptors. Further binding analysis of aripiprazole has established a broader pharmacological profile, including partial agonist actions at serotonin (5-hydroxytryptamine, 5-HT) receptors $5-\mathrm{HT}_{1 \mathrm{~A}}$ and $5-\mathrm{HT}_{2 \mathrm{C}}$, and antagonism of $5-\mathrm{HT}_{2 \mathrm{~A}}$ (Jordan et al, 2002).

Short-term randomised controlled trials of aripiprazole indicate an efficacious drug (for positive and negative symptoms) with a good safety and tolerability record in patients with acute relapse of schizophrenia or schizoaffective disorder (Marder et al, 2003; Potkin et al, 2003).

\section{Bifeprunox}

In September 2003 bifeprunox (developed by Solvay Pharmaceuticals and H. Lundbeck $\mathrm{A} / \mathrm{S}$ ) entered the phase III stage of clinical trials in schizophrenia. Preclinical studies indicated that the compound was a putative atypical antipsychotic with a pharmacological profile similar to aripiprazole. Preliminary preclinical analysis demonstrates that bifeprunox modulates animal behaviour induced by dopamine hyperactivity or hypoactivity and, in contrast to a D2 antagonist (haloperidol), bifeprunox decreases dopamine and 5-HT levels in the rat nucleus accumbens (Lieberman, 2004). Based on these observations, bifeprunox was classified as a partial agonist at $\mathrm{D} 2$ and $5-\mathrm{HT}_{1 \mathrm{~A}}$ receptors. Bifeprunox was also successful in reducing animal behaviour associated with schizophrenia-like symptoms and extrapyramidal side-effects.

\section{CONCLUSIONS}

Unlike the conventional antipsychotic agents, modern atypical antipsychotics have a lower propensity to cause extrapyramidal side-effects and to improve negative symptoms. Atypical antipsychotics demonstrate affinity for dopamine, serotonin and other neurotransmitter systems, but their precise mechanism of action is unknown. Several hypotheses have arisen to attempt to characterise the 'atypicality' of a drug, including a high $5-\mathrm{HT}_{2 \mathrm{~A}} / \mathrm{D} 2$ binding ratio and fast dissociation from D2 receptors (Meltzer et al, 1989; Kapur \& Seeman, 2001). The D2 receptor partial agonists represent a class of drugs that may have novel atypical properties. The therapeutic benefits of these drugs may reflect their action as dopamine system stabilisers in the presence of a potential cortical and subcortical dopamine imbalance in schizophrenia. All antipsychotic drugs produce adverse effects and are associated with variable response to treatment. Consequently, there is still a requirement for effective, safe and well-tolerated drugs for treating the symptoms of schizophrenia. The reviewed evidence suggests a promising future for dopamine receptor partial agonists in the treatment of patients with schizophrenia.

\section{DECLARATION OF INTEREST}

We were eager to write a partial agonism review without interference from the manufacturers of aripiprazole (Bristol-Myers Squibb/Otsuka) and bifeprunox (Solvay Pharmaceuticals and $H$. Lundbeck $A / S$ ). Bifeprunox is at an earlier stage in its clinical development and therefore the publication base for this drug is limited. However, we were anxious for this editorial to be balanced and not be an advertorial for aripiprazole. A.A.B. has no conflict of interest. R.W.K. is currently negotiating for funding for functional magnetic resonance imaging studies on both aripiprazole and bifeprunox from both
Bristol-Myers Squibb and Lundbeck, and has also acted as principal investigator for clinical trials of aripiprazole and sertindole (a Lundbeck product).

\section{REFERENCES}

Abi Dhargam, A. \& Moore, H. (2003) Prefrontal dopamine transmission at DI receptors and the pathology of schizophrenia. Neuroscientist, 5, 404-416.

Andreasen, N. C., Rezai, K., Alliger, R., et al (1992) Hypofrontality in neuroleptic-naïve patients and in patients with chronic schizophrenia. Assessment with xenon 133 single-photon emission computed tomography and the Tower of London. Archives of General Psychiatry, 49, 943-958.

Ariens, E. J. (1964) Molecular Pharmacology. New York: Academic Press.

Ariens, E. J. \& Simonis, A. M. (1964) A molecular basis for drug action. Journal of Pharmacy and Pharmacology, 16, 289-296.

Ariens, E. J., Simonis, A. M. \& Van Rossum, J. M. (1964) Drug-receptor interaction: interaction of one or more drugs with one receptor system. In Molecular Pharmacology (ed. E. J. Ariens), p. 17I. New York: Academic Press.

Breier, A., Su, T. P., Saunders, R., et al (1997) Schizophrenia is associated with elevated amphetamineinduced synaptic dopamine concentrations: evidence from a novel positron emission tomography method. Proceedings of the National Academy of Sciences of the United States of America, 94, 2569-2574.

Burris, K. D., Molski, T. F., Xu, C., et al (2002) Aripiprazole, a novel antipsychotic, is a high-affinity partial agonist at human dopamine D2 receptors. Journal of Pharmacology and Experimental Therapeutics, 302, 38I-389.

Carlsson, A. \& Lindqvist, M. (1963) Effect of chlorpromazine or haloperidol on formation of 3methoxytyramine and normetanephrine in mouse brain. Acta Pharmacologica et Toxicologica, 20, 140-144.

Carter, C. J. \& Pycock, C. J. (1979) The effects of 5,7dihydroxytryptamine lesions of extrapyramidal and mesolimbic sites on spontaneous motor behaviour, and amphetamine-induced stereotypy. NaunynSchmiedeberg's Archives of Pharmacology, 308, 5I-54.

Chio, C. L., Lajiness, M. E. \& Huff, R. M. (1994) Activation of heterologously expressed D3 dopamine receptors: comparison with D2 dopamine receptors. Molecular Pharmacology, 45, 5I-60.

Clark, D., Hjorth, S. \& Carisson, A. (1985)

Dopamine-receptor agonists: mechanisms underlying autoreceptor selectivity. I. Review of the evidence. Journal of Neural Transmission, 62, 1-52.

Creese, I., Burt, D. R. \& Snyder, S. H. (1976) Dopamine receptor binding predicts clinical and pharmacological potencies of antischizophrenic drugs. Science, 192, 48I-483.

Egan, M. F., Goldberg, T. E., Kolachana, B. S., et al (200I) Effect of COMT Vall08/158 Met genotype on frontal lobe function and risk for schizophrenia. Proceedings of the National Academy of Sciences of the United States of America, 98, 6917-6922.

Elsworth, J. D. \& Roth, R. H. (1997) Dopamine autoreceptor pharmacology and function. In I: Dopamine Receptors (ed. R. L. Neve), pp 232-265. Totowa, NJ: Humana Press. 
Grunder, G., Carlsson, A. \& Wong, D. (2003) Mechanisms of new antipsychotic medications. Archives of General Psychiatry, 60, 974-977.

Jordan, S., Koprivica, V., Chen, R., et al (2002) The antipsychotic aripiprazole is a potent, partial agonist at the human 5-HTIA receptor. European Journal of Pharmacology, 441, 137-140.

Kapur, S. \& Mamo, D. (2003) Half a century of antipsychotics and still a central role for dopamine D(2)receptors. Progress in Neuropsychopharmacology and Biological Psychiatry, 27, 1081-1090.

Kapur, S. \& Seeman, P. (200I) Does fast dissociation from the dopamine $\mathrm{d}(2)$ receptor explain the action of atypical antipsychotics? A new hypothesis. American Journal of Psychiatry, I58, 360-369.

Kapur, S., Zipursky, R., Jones, C., et al (2000) Relationship between dopamine D2 occupancy, clinical response and side effects: a double-blind PET study of first episode schizophrenia. American journal of Psychiatry, 157, 514-520.

Kerwin, R.W. (2000) From pharmacological profiles to clinical outcomes. International journal of Clinical Psychopharmacology, I5, SI-S4.

Kerwin, R.W. \& Osborne, S. (2000) Antipsychotic drugs. Medicine, 28, 23-25.

Kikuchi, T., Tottori, K., Uwahodo, Y., et al (1995) 7-(4 [4-(2,3-Dichlorophenyl)-I-piperazinyl]butyloxy)-3,4dihydro-2(IH)-quinolinone (OPC-14597), a new putative antipsychotic drug with both presynaptic dopamine autoreceptor agonistic activity and postsynaptic D2 receptor antagonistic activity. Journa of Pharmacology and Experimental Therapeutics, 274 329-336.

Lahti, A. C., Weiler, M. A., Corey, P. K., et al (1998) Antipsychotic properties of (-)-3-(3-hydroxyphenyl)$\mathrm{N}$-n-propylpiperidine (preclamol) in schizophrenia. Biological Psychiatry, 43, 2-II.

Lieberman, J. A. (2004) Dopamine partial agonists: a new class of antipsychotic. CNS Drugs, 18, 25I-267.

Marder, S. R., McQuade, R. D., Stock, E., et al (2003) Aripiprazole in the treatment of schizophrenia: safety

A. A. BOLONNA BSc(Hon), PhD, R.W. KERWIN, MA, PhD, MB BChir, DSc, FRCPsych, Section of Clinical Neuropharmacology, Institute of Psychiatry, London, UK

Correspondence: Professor R.W. Kerwin, Section of Clinical Neuropharmacology, Institute of Psychiatry, London SE5 8AF,UK. E-mail: spklrwk@iop.kcl.ac.uk

(First received 17 March 2004, accepted 21 June 2004)

and tolerability in short-term, placebo-controlled trials. Schizophrenia Research, 6I, 123-136.

Meltzer, H. Y. (1999) The role of serotonin in antipsychotic drug action. Neuropsychopharmacology, 2I, sl06-sll5.

\section{Meltzer, H.Y., Matsubara, S. \& Lee, J. C. (1989)}

Classification of typical and atypical antipsychotic drugs on the basis of dopamine D-I, D-2 and serotonin 2 pKi values. Journal of Pharmacology and Experimental Therapeutics, 25I, 238-246.

Ohmori, T., Koyama, T., Inoue, T., et al (1993) B-HT 920, a dopamine D2 agonist, in the treatment of negative symptoms of chronic schizophrenia. Biological Psychiatry, 33, 687-693.

Pilowsky, L., Costa, D. C., Ell, P. J., et al (1992)

Clozapine, single photon emission tomography and the dopamine D2 receptor blockade hypothesis of schizophrenia. Lancet, 340, 199-202.

Potkin, S. G., Saha, A. R., Kujawa, M. J., et al (2003) Aripiprazole, an antipsychotic with a novel mechanism of action, and risperidone vs placebo in patients with schizophrenia and schizoaffective disorder. Archives of General Psychiatry, 60, 681-690.

Pycock, C. J., Carter, C. J. \& Kerwin, R.W. (1980a) Effect of 6-hydroxydopamine lesions of the medial prefrontal cortex on neurotransmitter systems in subcortical sites in the rat. Journal of Neurochemistry, 34 91-99.

Pycock, C. J., Kerwin, R. W. \& Carter, C. J. (1980b) Effect of lesions of cortical dopamine terminals on subcortical dopamine receptors in the rat. Nature, 286 , 74-77.
Richelson, E. (1999) Receptor pharmacology of neuroleptics: relation to clinical effects. Journal of Clinical Psychiatry, 60, 5-14.

Seeman, P. \& Lee, T. (1975) Antipsychotic drugs: direct correlation between clinical potency and presynaptic activity on dopamine neurons. Science, 188, 1217-1219.

Stephenson, R. P. (1956) A modification of receptor theory. British Journal of Pharmacology, II, 379-393.

Tamminga, C. A. (2002) Partial dopamine agonists in the treatment of psychosis. Journal of Neural Transmission, 109, $411-420$.

Thierry, A. M., Stinus, L., Blanc, G., et al (1973) Some evidence for the existence of dopaminergic neurons in the rat cortex. Brain Research, 50, 230-234.

Weinberger, D. R. (1987) Implications of normal brain development for the pathogenesis of schizophrenia. Archives of General Psychiatry, 44, 660-669.

Weinberger, D. R. \& Berman, K. F. (1996) Prefronta function in schizophrenia: confounds and controversies. Philosophical Transactions of the Royal Society of London. Series B, Biological Sciences, 35I, 1495-1503.

Weinberger, D. R., Berman, K. F. \& Illowsky, B. P. (1988) Physiological dysfunction of dorsolateral prefrontal cortex in schizophrenia. III. A new cohort and evidence for a monoaminergic mechanism. Archives of General Psychiatry, 45, 609-615.

Wetzel, H., Hillert, A., Grunder, G., et al (1994) Roxindole, a dopamine autoreceptor agonist, in the treatment of positive and negative schizophrenic symptoms. American Journal of Psychiatry, I5I, 1499-1502. 